\title{
Níveis de fósforo e cálcio em dietas para codornas japonesas em postura
}

\author{
Carlos Henrique Rocha Costa ${ }^{1}$, Sergio Luiz de Toledo Barreto ${ }^{2}$, Weyllison César Oliveira \\ Moura $^{3}$, Renata de Souza Reis ${ }^{4}$, Carla Daniela Suguimoto Leite ${ }^{4}$, Gustavo Vaz Corrêa Maia ${ }^{5}$ \\ ${ }^{1}$ Doutorando em Zootecnia da Universidade Federal de Viçosa. \\ 2 Universidade Federal de Viçosa - Departamento de Zootecnia, s/n - Campus Universitário - Viçosa - MG. \\ ${ }^{3}$ Mestrando em Zootecnia da Universidade Federal de Viçosa. \\ ${ }^{4}$ Graduação em Zootecnia da Universidade Federal de Viçosa. \\ ${ }^{5}$ Mestrando em Zootecnia da Universidade Federal de Lavras.
}

RESUMO - Conduziu-se um experimento com o objetivo de verificar o efeito de diferentes níveis de fósforo disponível (Pd) e de cálcio (Ca) na dieta sobre o desempenho, a qualidade dos ovos e o perfil nutricional do tecido ósseo de codornas japonesas durante a fase inicial de postura. Foram utilizadas 700 codornas japonesas, com 61 dias de idade, distribuídas em 70 unidades experimentais de dez aves. O delineamento foi inteiramente casualizado em esquema fatorial $5 \times 2$, composto de cinco níveis de Pd $(0,15 ; 0,25 ; 0,35 ; 0,45$ e $0,55 \%)$ e dois de Ca $(2,5$ e $3,2 \%)$, com sete repetições por tratamento. As dietas experimentais foram isoprotéicas (20,0\% PB), isocalóricas (2.900 kcal EM/kg) e isoaminoacídicas. Os níveis de Pd influenciaram de forma quadrática a altura e o diâmetro médio dos ovos, o teor de Ca na casca e a porcentagem de Ca (2,5\% Ca) e P (3,2\%Ca) nos ossos. Houve melhora linear na produção de ovos comercializáveis e na porcentagem de P nos ossos (menor nível da Ca testado) até os níveis de 0,31 e 0,51\% de Pd, respectivamente, na dieta. Com o aumento dos níveis de Pd na dieta, a conversão alimentar por dúzia de ovos piorou de forma linear e a porcentagem e o peso de gema reduziram até os níveis 0,40 e $0,25 \%$ de Pd, respectivamente, na dieta. O peso, a porcentagem e a espessura de casca, o peso específico, o teor de Ca na casca e a porcentagem de Ca nos ossos foram influenciados pelos níveis de Ca na dieta. Não houve influência dos níveis de Ca e Pd sobre a produção de ovos, o consumo de ração, a massa de ovos, a conversão alimentar por massa de ovos, a viabilidade, o peso médio final das aves e a porcentagem e o peso de albúmen nos ovos. Níveis dietéticos de 2,5 e 0,31\% de Pd são suficientes para proporcionar bom desempenho produtivo e para manutenção satisfatória da qualidade dos ovos e do perfil nutricional do tecido ósseo de codornas japonesas durante a fase inicial de postura.

Palavras-chave: Coturnix coturnix japonica, desempenho produtivo, qualidade do ovo, perfil nutricional

\section{Levels of phosphorus and calcium in diets of laying Japanese quails}

ABSTRACT - An experiment was conducted with the objective to verify the effect of different levels of available phosphorus (aP) and of calcium (Ca) in the diet on the performance, the quality of eggs and the nutritional status of the bone tissue of japanese quails during the initial laying phase. A total of 700 japanese quails, with 61 days of age, distributed in 70 experimental units with 10 birds each were used. A completely randomized experimental design was use, in a $5 \times 2$ factorial arrangement with five levels of aP $(0.15 ; 0.25 ; 0.35 ; 0.45$ e $0,55 \%)$ and two levels of Ca $(2.5$ e $3.2 \%)$, with seven replicates per treatments. The experimental diets were isoprotéicas (20.0\% CP), isocalóricas (2.900 kcal ME $/ \mathrm{kg})$ and isoaminoacids. The levels of aP influenced by a quadratic form, the height and the average diameter of the eggs, the Ca egg shell content and percentage of $\mathrm{Ca}(2.5 \% \mathrm{Ca})$ and $\mathrm{P}(3.2 \% \mathrm{Ca})$ in the bones. There was a linear improvement for the commercial egg production and percentage of $\mathrm{P}$ in the bones (lower level of tested $\mathrm{Ca}$ ), up to the level of $0.31 \%$ and of $0.51 \% \mathrm{P}$, respectively, in the diet. As aP levels increased in the diet, the conversion for dozen of eggs linearly decreased and the percentage and yolk weight reduced up to the levels of 0.40 and $0.25 \%$ of aP, respectively, in the diet. The shell weight, percentage and thickness, specific weight, shell Ca content and percentage of $\mathrm{Ca}$ in the bones were influenced by the Ca levels in the diet. There was no influence of the $\mathrm{Ca}$ and a aP levels on eggs production, ration consumption, egg mass, feed conversion per eggs mass, viability, final average weight of the birds and percentage and weight of albumen in the eggs. Dietary levels of 2.5 and $0.31 \%$ aP are enough to provide good productive performance and satisfactory maintenance of the quality of eggs and nutritional status of bone tissues of Japanese quails during the initial laying period.

Key Words: Coturnix coturnix japonica, egg quality, nutritional status, productive performance 


\section{Introdução}

A criação de codornas no Brasil iniciou-se no final da década de 50 e se destacou mais nos anos de 1986 a 1988, quando houve superprodução de ovos, ocasionando prejuízos a produtores, com consideráveis perdas na produção e exploração dessas aves. Segundo Barreto et al. (2007), tem-se verificado retomada crescente na exploração da coturnicultura nacional, principalmente nas regiões Sudeste e Sul do País.

Os principais fatores que têm contribuído para a criação de codornas são o rápido crescimento, a maturidade sexual precoce (40 a 45 dias), a alta taxa de postura (em média 300 ovos/ave/ano), a elevada densidade de criação (90 a 106 aves $/ \mathrm{m}^{2}$ ), a elevada vida produtiva (14 a 18 meses), o baixo investimento e o rápido retorno do capital investido. Essas vantagens têm despertado interesses de pesquisadores da área avícola, no sentido de desenvolver trabalhos que contribuam com maior aprimoramento desta exploração. Segundo Fujikura (2002), a coturnicultura se destaca a cada ano como atividade produtiva no mercado agropecuário brasileiro. Na década de 90, houve grande crescimento na produção de ovos, em decorrência da mudança nas características dos mercados atacadistas e varejistas, uma vez que os ovos comercializados preferencialmente in natura passaram também a ser processados em indústrias beneficiadoras, originando os ovos descascados ou em conserva, muito utilizados em churrascarias, restaurantes, bares e lanchonetes.

Nos anos de 1999 e 2000, houve aumento de quase $17 \%$ no plantel de codornas, com aumento de $27 \%$ na produção de ovos. Em 2001 a estimativa era de aproximadamente seis milhões de aves e produção de 93.334 milhões de dúzias de ovos (IBGE, 2003). Embora a produção em escala tenha aumentando nos últimos anos, pouco se conhece sobre o manejo correto e a nutrição adequada de codornas. Dessa forma, para viabilizar a exploração racional, é necessária a realização de pesquisas objetivando a adoção de programas corretos de alimentação e práticas de manejo e sanidade. Além disso, as formulações de rações para essas aves se baseiam muitas vezes em dados pouco coerentes com as condições brasileiras, o que compromete dados de produtividade, em razão da escassez de trabalhos nacionais.

Entre os estudos dos níveis nutricionais, pouco se pesquisa sobre os minerais, nutrientes essenciais na formação do esqueleto e da composição da casca dos ovos e que exercem outras funções bioquímicas importantes no organismo. Assim, realizou-se este trabalho com o objetivo de determinar os níveis de fósforo disponível e de cálcio na dieta de codornas japonesas em postura.

\section{Material e Métodos}

O experimento foi realizado no setor de Avicultura do Departamento de Zootecnia da Universidade Federal de Viçosa, MG, no período de setembro a novembro de 2005. Foram utilizadas 700 codornas japonesas (Coturnix coturnix japonica) em postura, com 61 dias de idade, durante os quatro períodos experimentais de 21 dias.

Antes de iniciarem a postura, as aves foram pesadas individualmente aos 37 dias de idade. Aquelas com peso médio corporal de $125 \mathrm{~g}$ foram selecionadas e posteriormente alojadas em gaiolas de arame galvanizado, com dimensões de $47 \times 23,5 \times 16 \mathrm{~cm}$ (comprimento $\times$ largura $\times$ altura), dispostas em duas baterias de três andares. Cada andar foi composto de 12 gaiolas (seis posicionadas na frente e seis atrás) com capacidade individual para dez aves, mantendo-se área de 110,45 cm²/ave. Na distribuição das aves, optou-se pela uniformidade em postura, e não em peso corporal, em razão do provável estresse sofrido pelas aves no início do experimento. No início do período experimental, aos 61 dias de idade, as aves já apresentavam taxa de postura equivalente a $56 \%$.

O delineamento experimental foi inteiramente ao acaso, em esquema fatorial $5 \times 2$, composto de dez tratamentos (cinco níveis de Pd em combinação a dois níveis de Ca na dieta), com sete repetições e dez aves por unidade experimental. Foram formuladas dez dietas experimentais, isocalóricas, isoprotéicas e isoaminoacídicas, à base de milho e farelo de soja, com cinco níveis $(0,15$; 0,25; 0,35; 0,45 e 0,55\%) de Pd em combinação a dois níveis de Ca (2,5 e 3,2\%), constituindo-se os tratamentos experimentais (Tabela 1 ).

As dietas foram formuladas para atender às exigências nutricionais das codornas, segundo recomendações preconizadas pelo NRC (1994), exceto para as exigências de metionina + cistina digestível e lisina digestível, que foram baseadas nas recomendações de Pinto et al. (2003a,b). Foi considerada a energia metabolizável dos aminoácidos incorporados à dieta.

Água e ração foram fornecidas à vontade ao longo de todo o período experimental. As temperaturas $\left({ }^{\circ} \mathrm{C}\right)$ e a UR das salas foram monitoradas duas vezes ao dia, às $8 \mathrm{~h}$ e às 16h, por meio de termômetros de máxima e mínima e de bulbo seco e bulbo úmido posicionados em pontos estratégicos no galpão. As médias obtidas são apresentadas na Tabela 2.

O programa de iluminação iniciou-se aos 45 dias de idade das aves, com programa de luz inicial de 14 horas, com aumentos semanais de 30 minutos de luz até atingir 17 horas de luz diária, programa mantido até o término do período experimental. $\mathrm{O}$ fornecimento de luz foi controlado por um 
Tabela 1 - Composição das dietas experimentais (\% MN)

Table 1 - Compositions of the experimental diets (\% as-fed)

Ingrediente

Ingredient

Nível de P disponível (\%)

Available P level

\begin{tabular}{|c|c|c|c|c|c|c|c|c|c|}
\hline \multicolumn{10}{|c|}{$\begin{array}{c}\text { Nível de P disponível (\%) } \\
\text { Available P level }\end{array}$} \\
\hline \multicolumn{2}{|c|}{0,15} & \multicolumn{2}{|c|}{0,25} & \multicolumn{2}{|c|}{0,35} & \multicolumn{2}{|c|}{0,45} & \multicolumn{2}{|c|}{$0,55 \%$} \\
\hline \multicolumn{10}{|c|}{$\begin{array}{c}\text { Nível de Ca (\%) } \\
\text { Ca level (\%) }\end{array}$} \\
\hline 2,5 & 3,2 & 2,5 & 3,2 & 2,5 & 3,2 & 2,5 & 3,2 & 2,5 & 3,5 \\
\hline 54,380 & 50,582 & 54,380 & 50,582 & 54,380 & 50,582 & 54,380 & 50,582 & 54,380 & 50,582 \\
\hline 34,219 & 34,912 & 34,219 & 34,912 & 34,219 & 34,912 & 34,219 & 34,912 & 34,219 & 34,912 \\
\hline 3,017 & 4,303 & 3,017 & 4,303 & 3,017 & 4,303 & 3,017 & 4,303 & 3,017 & 4,303 \\
\hline 0,243 & 0,252 & 0,783 & 0,793 & 1,324 & 1,333 & 1,864 & 1,874 & 2,405 & 2,414 \\
\hline 6,099 & 7,915 & 5,754 & 7,569 & 5,409 & 7,225 & 5,065 & 6,880 & 4,720 & 6,535 \\
\hline 0,333 & 0,335 & 0,333 & 0,335 & 0,333 & 0,335 & 0,333 & 0,335 & 0,333 & 0,335 \\
\hline 0,048 & 0,048 & 0,048 & 0,048 & 0,048 & 0,048 & 0,048 & 0,048 & 0,048 & 0,048 \\
\hline 0,341 & 0,341 & 0,341 & 0,341 & 0,341 & 0,341 & 0,341 & 0,341 & 0,341 & 0,341 \\
\hline 0,165 & 0,165 & 0,165 & 0,165 & 0,165 & 0,165 & 0,165 & 0,165 & 0,165 & 0,165 \\
\hline 0,100 & 0,100 & 0,100 & 0,100 & 0,100 & 0,100 & 0,100 & 0,100 & 0,100 & 0,100 \\
\hline 0,010 & 0,010 & 0,010 & 0,010 & 0,010 & 0,010 & 0,010 & 0,010 & 0,010 & 0,010 \\
\hline 0,050 & 0,050 & 0,050 & 0,050 & 0,050 & 0,050 & 0,050 & 0,050 & 0,050 & 0,050 \\
\hline 0,100 & 0,100 & 0,100 & 0,100 & 0,100 & 0,100 & 0,100 & 0,100 & 0,100 & 0,100 \\
\hline 0,010 & 0,010 & 0,010 & 0,010 & 0,010 & 0,010 & 0,010 & 0,010 & 0,010 & 0,010 \\
\hline 0,885 & 0,886 & 0,690 & 0,690 & 0,494 & 0,495 & 0,298 & 0,299 & 0,102 & 0,103 \\
\hline
\end{tabular}

Milho (Corn)

Farelo de soja (45\%) (Soybean meal)

Óleo de soja (Soybean oil)

Fosfato bicálcico (Dicalcium phosphate)

Calcário (Limestone)

Sal (Salt)

L- Thr

DL-Met (99\%)

L- Lys.HCl (79\%)

Cloreto de colina (60\%) (Choline chloride)

Surmax ${ }^{1}$

Mistura mineral ${ }^{2}$ (Mineral mixture)

Mistura vitamínica ${ }^{3}$ (Vitamin mixture)

Antioxidante ${ }^{4}$ (Antioxidant)

Inerte $^{5}$ (Washed sand)

Composição nutricional calculada

Calculated nuritional composition

\begin{tabular}{|c|c|c|c|c|c|c|c|c|c|c|}
\hline PB(\%) (CP) & 20,00 & 20,00 & 20,00 & 20,00 & 20,00 & 20,00 & 20,00 & 20,00 & 20,00 & 20,00 \\
\hline EM (kcal/kg) (ME) & 2.900 & 2.900 & 2.900 & 2.900 & 2.900 & 2.900 & 2.900 & 2.900 & 2.900 & 2.900 \\
\hline P disponível (\%) (Available P) & 0,150 & 0,150 & 0,250 & 0,250 & 0,350 & 0,350 & 0,450 & 0,450 & 0,550 & 0,550 \\
\hline Lys total $(\%)$ & 1,209 & 1,209 & 1,209 & 1,209 & 1,209 & 1,209 & 1,209 & 1,209 & 1,209 & 1,209 \\
\hline Lys digestível (\%) (Digestible Lys) & 1,117 & 1,117 & 1,117 & 1,117 & 1,117 & 1,117 & 1,117 & 1,117 & 1,117 & 1,117 \\
\hline Met + Cys total $(\%)$ & 0,968 & 0,968 & 0,968 & 0,968 & 0,968 & 0,968 & 0,968 & 0,968 & 0,968 & 0,968 \\
\hline Thr digestível (\%) (Digestible Thr) & 0,730 & 0,730 & 0,730 & 0,730 & 0,730 & 0,730 & 0,730 & 0,730 & 0,730 & 0,730 \\
\hline Trp total $(\%)$ & 0,250 & 0,252 & 0,250 & 0,252 & 0,250 & & 0,250 & 0,252 & 0,250 & 0,252 \\
\hline Trp digestível (\%) (Digestible Trp) & 0,224 & 0,226 & 0,224 & 0,226 & 0,224 & 0,226 & 0,224 & 0,226 & 0,224 & 0,266 \\
\hline
\end{tabular}

${ }^{1}$ Avilamicina (10\%).

${ }^{2}$ Composição/kg de produto (Content/kg of product): vit. A - 12.000 .000 U.I.; vit $\mathrm{D}_{3}-3.600 .000$ U.I.; vit. E - 3.500 U.I.; vit $\mathrm{B}_{1}-2.500 \mathrm{mg} ;$ vit $\mathrm{B}_{2}-8.000 \mathrm{mg}$ vit $\mathrm{B}_{6}-5.000 \mathrm{mg}$; ácido pantotênico (pantothenic acid) - $12.000 \mathrm{mg}$; biotina (biotine) - $200 \mathrm{mg}$; vit. K - $3.000 \mathrm{mg}$; ácido fólico (folic acid) - $1.500 \mathrm{mg}$; ácido nicotínico (nicotinic acid) - $40.000 \mathrm{mg}$; vit. $\mathrm{B}_{12}-20.000 \mathrm{mg}$; Se - $150 \mathrm{mg}$; veículo q.s.p. (excipient) $-1.000 \mathrm{~g}$.

3 Composição/kg de produto (Content/kg of product): Mn - $160 \mathrm{~g} ; \mathrm{Fe}-100 \mathrm{~g} ; \mathrm{Zn}-100 \mathrm{~g} ; \mathrm{Cu}-20 \mathrm{~g}$; Co - $2 \mathrm{~g} ; \mathrm{I}-2 \mathrm{~g}$; excipiente q.s.p. (excipient) - $1.000 \mathrm{~g}$.

${ }^{4}$ Butil-hidróxi-tolueno.

${ }^{5}$ Areia lavada (Washed sand).

relógio automático (timer). Para avaliação do desempenho produtivo, foram avaliados a produção média de ovos por ave/dia (\%) e por ave/alojada, a viabilidade econômica das aves (\%), a produção de ovos comercializáveis (\%), o consumo de ração (g de ração/ave/dia), o peso dos ovos (g), a massa de ovos (g), a conversão alimentar ( $k g$ de ração por dúzia e por massa de ovos) e o peso médio final das aves (g).

Ao final do período experimental (84 dias), determinou-se a quantidade de ração consumida (g/ave/dia) em cada unidade experimental. Para isso, as sobras e os desperdícios foram pesados e descontados da quantidade de ração fornecida durante o período experimental. O número de aves mortas foi descontado do número total de aves de cada unidade experimental, o que possibilitou obter o correto consumo por ave.

A coleta dos ovos foi feita diariamente às $8 \mathrm{~h}$ e a produção média de ovos, expressa em porcentagem da média de aves do período (ave/dia), foi obtida computando-se os ovos inteiros, quebrados, trincados e anormais. Também foi calculado o número médio de ovos produzidos e classificados como comerciais, ou seja, sem defeitos, por meio da fórmula: (total de ovos viáveis produzidos/UE sobre o total de ovos produzidos/UE) $\times 100$.

Todos os ovos íntegros de cada unidade experimental foram coletados e pesados durante três dias consecutivos para obtenção do peso médio, que foi novamente calculado 
Tabela 2 - Temperatura e umidade relativa do ar no interior da instalação durante os períodos experimentais Table 2 - Temperature and air relative humidity inside the installation during experimental periods

\begin{tabular}{|c|c|c|c|c|}
\hline \multirow[t]{2}{*}{$\begin{array}{l}\text { Período e idade das aves (dias) } \\
\text { Period and bird age (days) }\end{array}$} & \multicolumn{3}{|c|}{$\begin{array}{c}\text { Temperatura }\left({ }^{\circ} \mathrm{C}\right) \\
\text { Temperature }\end{array}$} & \multirow[t]{2}{*}{$\begin{array}{c}\text { Umidade relativa (\%) } \\
\text { Relative humidity }\end{array}$} \\
\hline & $\begin{array}{l}\text { Mínima } \\
\text { Minimum }\end{array}$ & $\begin{array}{l}\text { Máxima } \\
\text { Maximum }\end{array}$ & $\begin{array}{l}\text { Média } \\
\text { Mean }\end{array}$ & \\
\hline 1으 (61 - 82) & 20,2 & 27,8 & 24,0 & 81,5 \\
\hline $2^{\underline{o}}(83-103)$ & 19,2 & 28,5 & 23,8 & 72,8 \\
\hline $3^{\mathrm{o}}(104-124)$ & 22,6 & 27,3 & 25,0 & 77,8 \\
\hline $4^{\circ}(125-145)$ & 21,4 & 24,6 & 23,0 & 77,4 \\
\hline Média (Mean) & 20,85 & 27,05 & - & 77,4 \\
\hline
\end{tabular}

a cada 21 dias. Ao final do experimento, o peso médio dos ovos foi recalculado a partir da média dos pesos médios de cada um dos três períodos.

Para obtenção da massa de ovos, tomou-se a produção de ovos multiplicada pelo peso médio dos ovos. A conversão alimentar foi obtida dividindo-se o consumo médio de ração por gramas de massa de ovos produzidos (conversão g/g) e o consumo médio de ração, em kg, por dúzia de ovos produzidos (conversão kg/dz).

O peso médio final foi obtido pela pesagem das aves de cada unidade experimental. Durante o experimento, foram observados e avaliados ainda alguns parâmetros de qualidade dos ovos e o perfil nutricional do tecido ósseo das aves: peso específico dos ovos $\left(\mathrm{g} / \mathrm{cm}^{3}\right)$; componentes do ovo (g); espessura de casca ( $\mathrm{mm}$ ); altura e diâmetro médio dos ovos (mm); porcentagem de cálcio e fósforo na casca do ovo (\%) e no tecido ósseo (\%).

Para obtenção do peso específico dos ovos, no 16ํㅜㅇ, 170 e 18 o dias de cada um dos quatro períodos experimentais, todos os ovos íntegros coletados foram imersos e avaliados em soluções de $\mathrm{NaCl}$ com densidade de 1,055 a $1,100 \mathrm{~g} / \mathrm{cm}^{3}$, com intervalos de $0,005 \mathrm{~g} / \mathrm{cm}^{3}$ entre elas. A densidade do ovo foi medida por meio de um densímetro da marca OM-5565.

Os componentes dos ovos foram avaliados considerando o peso do ovo, o peso da gema, o peso do albúmen, o peso da casca e as porcentagens de gema, albúmen e casca do ovo. Quatro ovos de cada repetição foram escolhidos segundo o peso médio de cada unidade experimental no 19으, 20으 e 21으 dias a cada 21 dias. Os ovos foram pesados individualmente em balança com precisão de 0,001 g e, posteriormente, foram identificados e quebrados com estilete. A gema de cada ovo foi pesada e registrada e a respectiva casca foi lavada e seca ao ar para obtenção de seu peso. $\mathrm{O}$ peso do albúmen foi calculado como a diferença entre o peso do ovo e o peso da gema somada ao peso da casca.

A espessura média da casca, incluindo a membrana, foi obtida após a secagem e pesagem, por meio da leitura de três pontos distintos na região equatorial, utilizando-se um paquímetro digital da marca MITUTOYO, com precisão de 0,01 mm (0,01 - 150,00 mm). As três medidas obtidas em cada casca foram transformadas em um valor médio por parcela.

Todos os ovos de cada repetição foram coletados no 19 으, $20^{\circ}$ e $21^{\underline{0}}$ dias, a cada 21 dias, para quantificação da altura e do diâmetro médio. As leituras foram realizadas na região equatorial e nos dois pólos de cada ovo recolhido utilizando-se também um paquímetro digital.

Durante todo o período experimental, as cascas dos ovos utilizadas para avaliação da espessura foram agrupadas por tratamento e por período e secas em estufa a $105^{\circ} \mathrm{C}$. Posteriormente, foram moídas para análises das porcentagens de cálcio e fósforo.

Ao final do experimento, 210 aves (três por parcela) foram abatidas por deslocamento cervical para retirada da tíbia e do fêmur direitos e esquerdos para determinação do conteúdo de fósforo e cálcio nas tíbias. Foram utilizadas como padrão as tíbias direita e esquerda. Como contraamostra, o fêmur foi armazenado em freezer para utilização em caso de necessidade.

Os ossos foram identificados por tratamento e repetição e, depois, foram pré-desengordurados, mantidos em estufa de ventilação forçada por 72 horas e triturados em moinho de bola. A solução mineral foi preparada conforme metodologia descrita por Silva (1998) utilizando-se os procedimentos da via úmida. Da solução mineral determinaram-se os teores de fósforo, pelo método colorimétrico, e de cálcio, pelo método de absorção atômica.

Os parâmetros avaliados foram submetidos à análise de variância a 5\% de probabilidade utilizando-se o Programa SAEG - Sistema para Análises Estatísticas e Genética (UFV, 2004). Posteriormente, os efeitos dos níveis de fósforo e de cálcio foram estimados por meio de análise das variáveis pelos modelos de regressão linear, quadrática e Linear Response Plateau, conforme o melhor ajustamento obtido para cada variável, considerando o comportamento biológico das aves e a menor soma de quadrado dos desvios obtida nas análises. Foi adotado o seguinte modelo estatístico: 


$$
Y i j k=\mu+C a i+P j+C a P i j+e i j k
$$

em que Yijk = observação $k$ da unidade experimental nos níveis de Cai, e níveis de $\mathrm{Pj} ; \mu$ = constante geral do experimento; Cai = efeito do nível de Cai (2,5 e 3,2\%); Pj = efeito do nível de $\mathrm{Pj}(0,15 ; 0,25 ; 0,35 ; 045$ e 0,55\%); CaPij = efeito da interação Ca $\times$ P; eijk = erro aleatório.

\section{Resultados e Discussão}

Não houve efeito da interação nível de Ca × nível de Pd da dieta sobre nenhum dos parâmetros de desempenho e de qualidade dos ovos estudados, portanto, os níveis de Ca e de Pd comportaram-se de forma independente e as variáveis foram analisadas pelos seus efeitos principais (Tabelas 3, 4, 5 e 6). No entanto, a interação dos níveis de $\mathrm{Ca} \times \mathrm{Pd}$ da dieta influenciou a porcentagem de Ca e de P no osso (Tabela 7).
Os níveis de Pd e de Ca não afetaram significativamente o consumo de ração (g), a produção de ovos por ave/dia (\%) e por ave alojada (\%), o peso médio dos ovos (g), a massa de ovos por ave/dia (g), a conversão alimentar por massa de ovos (g/g), a viabilidade das aves (\%) e o peso médio final das aves (g). No entanto, os níveis de Pd influenciaram a produção de ovos comerciais (\%) e a conversão alimentar por dúzia de ovos $(\mathrm{kg} / \mathrm{dz})$.

Dietas com 3,2\% de Ca proporcionaram, em valor absoluto, menor consumo de ração se comparadas às dietas com 2,5\% de Ca. Pedroso et al. (1999) também não encontraram diferenças significativas para essa variável mencionada em pesquisa na qual avaliaram os níveis de 2,5; 3,0 e 3,5\% de Ca na dieta de codornas. No caso do fósforo disponível, as aves alimentadas com as dietas formuladas com o menor nível (0,15\%) consumiram mais ração, mas não houve diferença significativa entre os tratamentos $(\mathrm{P}>0,05)$. Garcia et

Tabela 3 - Desempenho de codornas japonesas alimentadas com dietas com diferentes níveis de P disponível Table 3 - $\quad$ Performance of Japanese quails fed diets with different levels of available $P$

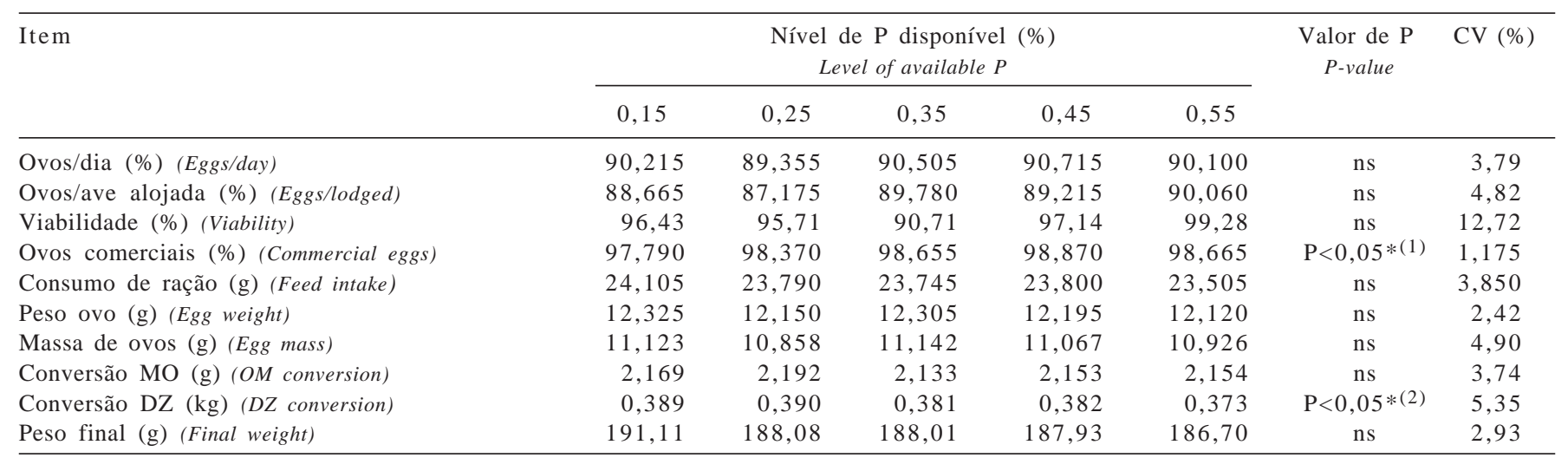

$* 1$ LRP $-\mathrm{Y}=96,9199+5,799 \times\left(\right.$ reta), $\mathrm{R}^{2}=1,00 ; \mathrm{Y}=98,7289$ (platô).

* 2 Efeito linear (linear effect); Regressão linear: $Y=0,397373-0,040321 X, R^{2}=0,83$.

ns $=$ Não-significativo $(P>0,05)($ not significant, $P>0.05)$.

Tabela 4 - Desempenho de codornas japonesas alimentadas com dietas com diferentes níveis de cálcio Table 4 - Performance of Japanese quails fed diets with different levels of Ca

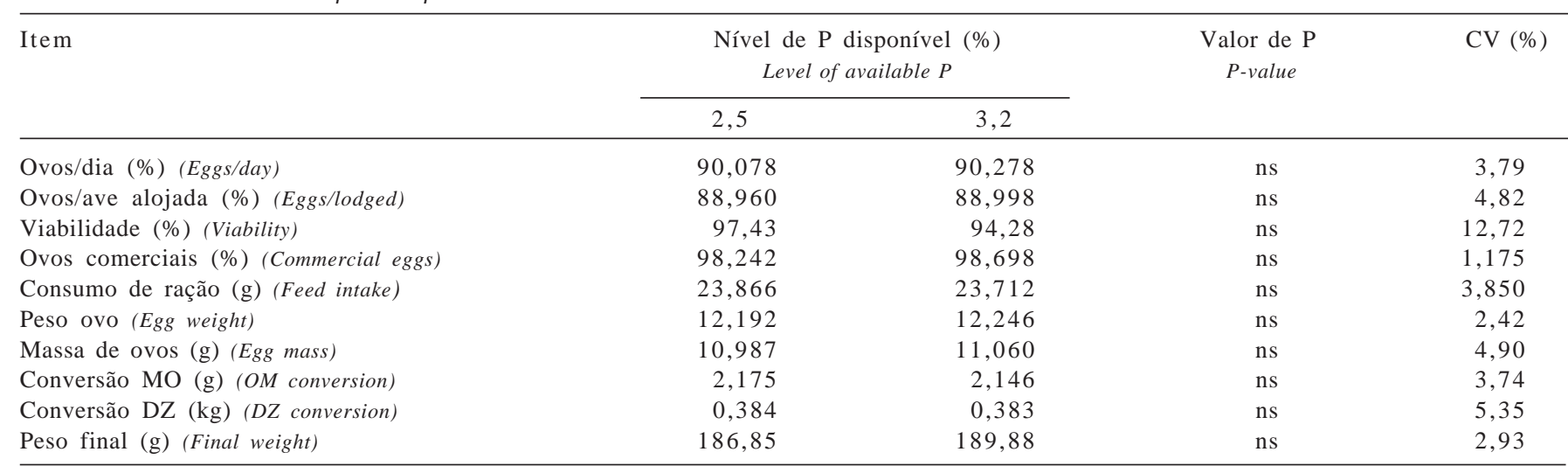

ns = Não-significativo $(P>0,05)$ (not significant, $P>0.05)$. 
Tabela 5 - Qualidade dos ovos de codornas japonesas alimentadas com dietas com diferentes níveis de fósforo disponível Table 5 - Egg quality of Japanese quails fed diets with different levels of available $P$

\begin{tabular}{|c|c|c|c|c|c|c|c|}
\hline \multirow[t]{2}{*}{ Item } & \multicolumn{5}{|c|}{$\begin{array}{l}\text { Nível de P disponível (\%) } \\
\text { Level of available P }\end{array}$} & \multirow[t]{2}{*}{$\begin{array}{l}\text { Valor de } \mathrm{P} \\
P \text {-value }\end{array}$} & \multirow[t]{2}{*}{ CV (\%) } \\
\hline & 0,15 & 0,25 & 0,35 & 0,45 & 0,55 & & \\
\hline Peso de casca (g) (Shell weight) & 0,958 & 0,960 & 0,968 & 0,959 & 0,956 & Ns & 2,96 \\
\hline Casca (\%) (Shell) & 7,81 & 7,92 & 7,88 & 7,88 & 7,88 & Ns & 2,214 \\
\hline Peso de albúmen (g) (Albumem weight) & 7,66 & 7,60 & 7,69 & 7,63 & 7,63 & Ns & 2,77 \\
\hline Gema (\%) (Yolk) & 29,77 & 29,48 & 29,44 & 29,40 & 29,21 & $\mathrm{P}<0,05 * 2$ & 2,161 \\
\hline Espessura de casca (mm) (Shell thickness) & 0,203 & 0,205 & 0,202 & 0,204 & 0,202 & Ns & 2,22 \\
\hline Altura dos ovos (mm) (Egg height) & 32,80 & 32,97 & 33,25 & 32,52 & 32,31 & $\mathrm{P}<0,05 * * 3$ & 2,461 \\
\hline Diâmetro dos ovos (mm) (Egg diameter) & 25,77 & 26,01 & 25,85 & 25,58 & 25,21 & $\mathrm{P}<0,05 * * 4$ & 2,165 \\
\hline Ca na casca (\%) (Ca in the shell) & 29,56 & 28,05 & 27,06 & 28,72 & 30,06 & $\mathrm{P}<0,05 * * 5$ & 8,801 \\
\hline P na casca $(\%)$ (P in the shell) & 0,333 & 0,342 & 0,346 & 0,371 & 0,348 & Ns & 11,132 \\
\hline
\end{tabular}

$* 1 \quad$ LRP $-Y=3,7687-0,757 X$ (reta); $Y=3,5795$ (platô).

*2 LRP - Y $=29,9809-1,657 X$ (reta); $Y=29,3076$ (platô).

$* * 3$ Efeito quadrático (Quadratic effect); $Y=31,9914+7,34133 X-12,5416 X^{2}, R^{2}=0,78$.

$* * 4$ Efeito quadrático (Quadratic effect); $Y=25,2689+5,02034 X-9,39592 X^{2}, R^{2}=0,97$

$* * 5$ Efeito quadrático (Quadratic effect); $Y=34,219-40,068 X+59,633 X^{2}, R^{2}=0,92$.

Ns Não-significativo, $P>0,05$ (not significant, $P>0.05$ ).

Tabela 6 - Qualidade dos ovos de codornas japonesas alimentadas com dietas com diferentes níveis de cálcio

Table 6 - Egg quality of Japanese quails fed diets with different levels of $\mathrm{Ca}$

\begin{tabular}{|c|c|c|c|c|}
\hline \multirow[t]{2}{*}{ Item } & \multicolumn{2}{|c|}{$\begin{array}{l}\text { Nível de Ca (\%) } \\
\text { Ca level (\%) }\end{array}$} & \multirow[t]{2}{*}{$\begin{array}{c}\text { Valor de } \mathrm{P} \\
P \text {-value }\end{array}$} & \multirow[t]{2}{*}{ CV \% } \\
\hline & 2,5 & 3,2 & & \\
\hline $\begin{array}{l}\text { Peso específico }\left(\mathrm{g} / \mathrm{cm}^{3}\right) \\
\text { Especific weight }\end{array}$ & 1,071 & 1,073 & $\mathrm{P}<0,01^{*}$ & 0,140 \\
\hline $\begin{array}{l}\text { Peso de casca (g) } \\
\text { Shell weight }\end{array}$ & 0,943 & 0,978 & $\mathrm{P}<0,01^{*}$ & 2,96 \\
\hline $\begin{array}{l}\text { Casca }(\%) \\
\text { Shell }\end{array}$ & 7,75 & 8,00 & $\mathrm{P}<0,01^{*}$ & 2,214 \\
\hline $\begin{array}{l}\text { Peso de albúmen (g) } \\
\text { Albumen weight }\end{array}$ & 7,62 & 7,66 & Ns & 2,77 \\
\hline $\begin{array}{l}\text { Albúmen (\%) } \\
\text { Albumen }\end{array}$ & 62,67 & 62,65 & Ns & 1,113 \\
\hline $\begin{array}{l}\text { Peso de gema (g) } \\
\text { Yolk weight }\end{array}$ & 3,60 & 3,59 & Ns & 2,966 \\
\hline $\begin{array}{l}\text { Gema }(\%) \\
\text { Yolk }\end{array}$ & 29,58 & 29,34 & Ns & 2,161 \\
\hline $\begin{array}{l}\text { Espessura de casca (mm) } \\
\text { Shell thickness }\end{array}$ & 0,199 & 0,207 & $\mathrm{P}<0,01^{*}$ & 2,22 \\
\hline $\begin{array}{l}\text { Altura dos ovos (mm) } \\
\text { Egg height }\end{array}$ & 32,63 & 32,92 & Ns & 2,461 \\
\hline $\begin{array}{l}\text { Diâmetro dos ovos (mm) } \\
\text { Egg diameter }\end{array}$ & 25,58 & 25,80 & Ns & 2,165 \\
\hline $\begin{array}{l}\text { Ca na casca }(\%) \\
\text { Ca in the shell }\end{array}$ & 30,06 & 27,33 & $\mathrm{P}<0,01^{*}$ & 8,801 \\
\hline $\begin{array}{l}\mathrm{P} \text { na casca }(\%) \\
P \text { in the shell }\end{array}$ & 0,353 & 0,343 & Ns & 11,132 \\
\hline
\end{tabular}

* Efeito significativo (Significant effect).

ns - Não-significativo, $\mathrm{P}>0,05$ (not significant, $P>0,05$ ).

al. (2000), estudando níveis de 2,5 a 4,0\% de Ca e 0,27 a 0,42\% de Pd na dieta, observaram que níveis crescentes de Ca diminuíram linearmente o consumo de ração e que o aumento dos níveis de Pd teve efeito quadrático $(\mathrm{P}<0,05)$ sobre o consumo, que foi maior no nível de $0,36 \%$ de Pd.

Não houve efeito significativo $(\mathrm{P}>0,05)$ dos níveis de Ca e de Pd da dieta sobre a produção de ovos/ave/dia, portanto, as dietas não influenciaram a taxa de postura diária das aves. Dietas com 3,2\% de Ca proporcionaram, em valores absolutos, aumento de $0,22 \%$ no número de ovos/ ave/dia, enquanto dietas com $0,45 \%$ de Pd promoveram, em valores absolutos, aumento de $1,5 \%$ na produção de ovos em comparação a dietas com $0,25 \%$ de Pd. Esses resultados estão de acordo com os encontrados por Pedroso et al. (1999), que não observaram diferença na porcentagem de postura ao avaliarem dietas contendo 2,5; 3,0 e 3,5\% de Ca combinados a 0,$25 ; 0,45 ; 0,65$ e $0,85 \%$ de Pd para codornas japonesas. No entanto, Garcia et al. (2000) avaliaram codornas japonesas no pico de postura alimentadas com dietas contendo 2,5 a 4,0\% de Ca e 0,27 a 0,42\% de Pd e observaram que os níveis 3,06\% de Ca e $0,36 \%$ de Pd proporcionaram aumento na produção de ovos. A produção média de ovos por ave alojada não foi afetada $(\mathrm{P}>0,05)$ pelos níveis dietéticos de Ca e Pd, uma vez que a produção de ovos/ave/ dia não variou significativamente $(\mathrm{P}>0,05)$ entre os níveis, tanto de Ca como de Pd, na dieta.

A viabilidade das aves não foi influenciada $(P>0,05)$ pelos níveis dos minerais estudados. Ressalta-se que são escassos os trabalhos científicos para determinação da produção de ovos por ave alojada para codornas. A viabilidade das aves é uma variável importante que deve ser bem analisada, uma vez que a mortalidade das codornas durante a fase de postura é muito mais elevada que a de galinhas poedeiras. 
Tabela 7 - Deposição de Ca e P no tecido ósseo de codornas japonesas alimentadas com dietas com diferentes níveis de cálcio e fósforo disponível

Table 7 - Deposition of $\mathrm{Ca}$ and $P$ in the bone tissue of Japanese quails fed diets with different levels of Ca and available $P$

\begin{tabular}{|c|c|c|c|}
\hline \multicolumn{2}{|c|}{ Item } & \multirow{2}{*}{$\begin{array}{c}\text { Cálcio no osso (\%) } \\
\text { Calcium in bone }\end{array}$} & \multirow{2}{*}{$\begin{array}{c}\text { Fósforo no osso (\%) } \\
\text { Phosphorus in bone }\end{array}$} \\
\hline $\begin{array}{l}\text { Nível de P disponível (\%) } \\
\text { Available Pd level }\end{array}$ & $\begin{array}{c}\text { Nível de Ca (\%) } \\
\text { Ca level }\end{array}$ & & \\
\hline $\begin{array}{l}0,15 \\
0,25 \\
0,35 \\
0,45 \\
0,55\end{array}$ & $\begin{array}{l}2,5 \\
2,5 \\
2,5 \\
2,5 \\
2,5\end{array}$ & $\begin{array}{c}20,26 \\
20,92 \\
23,30 \\
23,57 \\
22,83 \\
\mathrm{P}<0,05 * * 2\end{array}$ & $\begin{array}{c}9,95 \\
10,43 \\
11,04 \\
11,18 \\
11,56 \\
\mathrm{P}<0,01^{* 1}\end{array}$ \\
\hline $\begin{array}{c}\text { Nível de P disponível (\%) } \\
\text { Available Pd level }\end{array}$ & $\begin{array}{c}\text { Nível de Ca (\%) } \\
\text { Ca level }\end{array}$ & & \\
\hline $\begin{array}{l}0,15 \\
0,25 \\
0,35 \\
0,45 \\
0,55\end{array}$ & $\begin{array}{l}3,2 \\
3,2 \\
3,2 \\
3,2 \\
3,2\end{array}$ & $\begin{array}{c}22,10 \\
21,05 \\
22,19 \\
21,32 \\
22,70 \\
\text { ns }\end{array}$ & $\begin{array}{c}10,91 \\
10,11 \\
10,45 \\
10,62 \\
11,38 \\
\mathrm{P}<0,01 * * 3\end{array}$ \\
\hline & & 7,29 & 5,72 \\
\hline
\end{tabular}

$\star 1$ LRP $-Y=9,3616+4,289 X$ (reta); $Y=11,5594$ (platô).

$* \star 2$ Efeito quadrático (Quadratic effect); $Y=15,8595+32,3342 X-35,0827 X^{2}, R^{2}=0,88$

$* \star 3$ Efeito quadrático (Quadratic effect); $Y=12,3365+13,2240 X-20,9595 X^{2}, R^{2}=0,90$.

ns: Não-significativo $(P>0,05)$ (not significant, $P>0.05$ ).

O aumento dos níveis de Pd resultou em maior produção de ovos comercializáveis, o que não ocorreu com os dois níveis de Ca utilizados. Barreto et al. (2007) não encontraram influência dos níveis de Ca na qualidade dos ovos destinados à comercialização. Segundo esses autores, níveis de Ca na dieta abaixo da exigência de 2,5\% de Ca, determinada pelo NRC (1994), não interferem na produção de ovos comerciais no período de 56 até 171 dias de idade.

Os níveis de Ca e Pd não influenciaram $(\mathrm{P}>0,05)$ o peso médio dos ovos, o que pode ser explicado pela redução no consumo de ração com o aumento dos níveis de Ca e Pd na dieta, conforme verificado por Junqueira (1993), que observou não só diminuição no peso dos ovos, mas também redução do consumo de ração pelas aves. Pedroso et al. (1999), utilizando níveis de 2,5 a 3,5\% de Ca e de $0,25 \%$ a $0,85 \%$ de $\mathrm{Pd}$ na dieta das aves, não verificaram influência significativa do Ca e do Pd sobre o peso médio dos ovos. O mesmo foi observado por Masukawa et al. (2001), que conduziram trabalho com níveis de Ca na dieta de codornas japonesas. Garcia et al. (2000), no entanto, testaram níveis de 0,27 a $0,42 \%$ de Pd e de 2,5 a 4,0\% de Ca na dieta e observaram diminuição linear $(\mathrm{P}<0,01)$ no peso dos ovos conforme aumentaram os níveis de Ca na ração das codornas.

A massa de ovos não foi influenciada pelos níveis de Pd e Ca estudados, provavelmente porque não houve influência $(\mathrm{P}>0,05)$ dos níveis desses minerais nas dietas sobre a produção e o peso médio dos ovos. Os níveis de Pd e de Ca não afetaram ainda a conversão alimentar por massa de ovos ( $\mathrm{P}>0,05)$, o que pode ser explicado pelo maior nível de Ca na dieta (3,2\%) e pela ausência de efeito dos níveis de Pd sobre o consumo de ração, a produção de ovos e a massa de ovos. Garcia et al. (2000), no entanto, observaram efeito quadrático dos níveis de Pd sobre a conversão alimentar $(\mathrm{kg} / \mathrm{kg})$, que foi melhor no nível de 0,36\% de Pd.

Observou-se melhoria linear $(\mathrm{P}<0,05)$ dos níveis de $\mathrm{Pd}$ sobre a conversão alimentar por dúzia de ovos, no entanto, não foi possível estimar o nível de Pd que maximizou esta variável, conforme a equação de regressão ( $\mathrm{Y}=0,397373$ 0,040321X; $\left.\mathrm{R}^{2}=0,83\right)$. Garcia et al. (2000), observaram melhoria linear na conversão alimentar (kg/dz) com o aumento dos níveis de Pd, todavia, os níveis de Ca não influenciaram essa variável. Barreto et al. (2007) e Masukawa et al. (1996) avaliaram diferentes níveis de Ca (1,6 a 3,6\% e 2,0 a 3,5\%), respectivamente, na dieta de codornas japonesas em fase de postura e observaram que os níveis de Ca das dietas pioraram linearmente a conversão alimentar.

A dieta formulada com $3,2 \%$ de Ca proporcionou às aves peso final $1,6 \%$ superior ao obtido com a dieta com 2,5\% de Ca, porém, esse aumento não foi significativo no nível de 5\% de probabilidade. 
O aumento dos níveis de Pd na dieta elevou linearmente $(\mathrm{P}<0,05)$ a porcentagem de gema até o nível de $0,25 \%$ e também o peso da gema até o nível de $0,40 \%$ de Pd. Além disso, indicou de forma quadrática $(\mathrm{P}<0,05)$ que o nível que minimiza a porcentagem de Ca na casca é de $0,34 \%$ de Pd. Também houve efeito quadrático $(\mathrm{P}<0,05)$ para altura e diâmetro dos ovos; os níveis ótimos foram 0,29 e $0,27 \%$, respectivamente. O nível de $3,2 \%$ de Ca na dieta aumentou $(\mathrm{P}<0,01)$ o peso, o peso específico e a porcentagem e espessura de casca dos ovos e reduziu a porcentagem de Ca na casca.

As aves alimentadas com a dieta contendo 3,2\% de Ca produziram ovos com gravidade específica $0,2 \%$ maior, o que está de acordo com resultados obtidos por Luz (2002), que testou níveis de 2,0; 2,5; 3,0 e 3,5\% de Ca e observou efeito linear crescente das dietas sobre o peso específico do ovo. Os resultados obtidos neste estudo estão de acordo também com os encontrados por Maggioni et al (1998) ao estudarem os níveis de 3,5; 4,5 e 5,5\% de Ca e de 0,3 e $0,4 \%$ de Pd em dietas para galinhas poedeiras semipesadas. No entanto, Pedroso et al. (1999), trabalhando com três níveis de 2,5; 3,0 e 3,5\% de Ca em combinação a 0,25; 0,45; 0,65 e 0,85\% de Pd, obtiveram interação significativa dos minerais utilizados.

As aves alimentadas com a dieta contendo 3,2\% de Ca produziram ovos com $3,6 \%$ a mais de casca que aquelas que receberam 2,5\% de Ca na dieta. Esses resultados estão de acordo com afirmativa de Barreto et al. (2007) de que aves alimentadas com dietas contendo 3,42\% de Ca apresentam maior peso médio de casca dos ovos em comparação a aves alimentadas com níveis inferiores.

O aumento do nível de Ca na dieta elevou $(\mathrm{P}<0,01)$ a porcentagem de casca, o que está relacionado à diminuição da taxa de postura (Murata, 1995) ou à redução do peso dos ovos (Ousterhouth, 1980). No entanto, o aumento de 2,5 para 3,2\% de Ca na dieta não ocasionou diminuição na taxa de postura nem no peso dos ovos, e sim aumento, em valor absoluto, de 0,22 e 0,44\%, respectivamente, para essas variáveis.

Não houve influência dos níveis de Ca e de Pd (P>0,05) no peso e na porcentagem de albúmen dos ovos. Segundo Cavalheiro et al. (1983), a menor porção de $\mathrm{P}$ utilizada pelas poedeiras durante o processo de formação do ovo é usada na formação da clara e a maior porção é direcionada para a gema sob a forma de fosfolipídeos e fosfoproteínas. De acordo com os resultados encontrados, houve efeito significativo $(\mathrm{P}<0,05)$ das dietas sobre o peso e a porcentagem de gema dos ovos. Portanto, suplementações superiores a 0,25 e $0,40 \%$ de Pd em dietas para codornas japonesas em fase inicial de postura não promove redução no peso e na porcentagem de gema dos ovos, respectivamente. À medida que níveis de Pd na dieta aumentaram, houve redução linear, de ambas as variáveis, até os níveis de 0,25 e $0,40 \%$ de Pd, nos quais houve estabilização, conforme demonstrado nas equações: (\% gema - Y = 29,9809 1,657X (reta); $\mathrm{R}^{2}=1,00 ; \mathrm{Y}=29,3076$ (platô)) e (peso gema $-Y=3,7687-0,757 X$ (reta); $R^{2}=1,00 ; Y=3,5795$ (platô)).

É possível que haja um limite fisiológico da ave para deposição de Pd na gema. Então, todo o excesso de P consumido pode ter sido eliminado via excreta ou parte dele foi depositada nos ossos, hipótese reforçada pelo fato de os níveis de Pd não terem influenciado a porcentagem de casca e de albúmen dos ovos.

A espessura de casca foi influenciada $(\mathrm{P}<0,01)$ pelo aumento do nível de Ca na dieta, no entanto, não foi afetada pelos níveis de Pd $(\mathrm{P}>0,05)$ testados. Segundo Hamilton \& Sibbald (1997), a redução do nível de P dietético com o avanço da idade das aves melhora a qualidade da casca do ovo. Roland \& Harms (1976) e Mogin \& Sauveur (1979) acreditam que as poedeiras utilizam melhor o Ca reabsorvido dos ossos trazendo o P juntamente com Ca quando baixos níveis dietéticos de P são utilizados. Rodriguez et al. (1984), por sua vez, observaram efeito linear negativo para a espessura de casca de 0,$405 ; 0,393$ e $0,388 \mathrm{~mm}$ com o uso de dieta com nível de 0,15; 0,30 e 0,45\% de Pd, respectivamente, da 22 a $70^{\mathrm{a}}$ semana de idade de poedeiras.

Os resultados observados para o Ca estão de acordo com o encontrado por Barreto et al. (2007), que obtiveram bons resultados para a espessura da casca dos ovos de codornas alimentadas com dietas contendo 3,2\% de Ca. Entretanto, em trabalho conduzido por Masukawa et al. (2001), não foi observado efeito significativo dos níveis dietéticos de Ca (2,0; 2,5; 3,0 e 3,5\%) sobre a espessura de casca dos ovos de codornas japonesas. O mesmo foi observado por Pedroso et al. (1999), que não encontraram efeito significativo para espessura de casca de ovos de codornas alimentadas com dietas com níveis de 2,5 a 3,5\% de $\mathrm{Ca}$ combinados a níveis de 0,25 a $0,85 \%$ de Pd.

Os níveis de Pd influenciaram de forma quadrática $(\mathrm{P}<0,05)$ a altura e o diâmetro médio dos ovos. Os valores de 0,29 e $0,27 \%$ de Pd foram os que maximizam as duas características, respectivamente. O tamanho do ovo está diretamente relacionado ao seu peso e à idade das aves em postura, no entanto, o peso médio dos ovos não variou entre os diferentes níveis de $\mathrm{P}$ consumido e as aves possuíam a mesma idade. Assim, não houve influência do peso do ovo e da idade das aves nos resultados encontrados.

Observou-se efeito quadrático $(\mathrm{P}<0,05)$ dos níveis de Pd da dieta ( $\left.\hat{\mathrm{Y}}=34,219-40,068 \mathrm{X}+59,633 \mathrm{X}^{2} ; \mathrm{R}^{2}=0,92\right)$ 
sobre a deposição de Ca na casca, que foi menor no nível de $0,34 \%$ de Pd. O maior nível de Ca $(3,2 \%)$ resultou em redução significativa $(\mathrm{P}<0,01)$ na concentração de $\mathrm{Ca}$ na casca. No entanto, Barreto et al. (2007) não notaram influência dos níveis de Ca na dieta sobre a porcentagem de Ca na casca, mesmo com a utilização de níveis de Ca inferiores ao recomendado pelo NRC (1994), como os níveis de 1,6; 2,0 e $2,4 \%$ de Ca na dieta.

A porcentagem de $\mathrm{P}$ na casca do ovo não foi influenciada ( $\mathrm{P}>0,05)$ pelos níveis de Ca e de Pd da dieta. Segundo Cavalheiro et al.(1983), apenas pequena quantidade do $\mathrm{P}$ utilizado na formação do ovo é depositada na casca para formação do fosfato de cálcio; a maior parte é depositada na gema do ovo e o restante na clara.

Com o desdobramento da interação, as concentrações de Ca nos ossos (Tabela 7) foram influenciadas de forma quadrática $(\mathrm{P}<0,05)$ pelos níveis de $\mathrm{Pd}$ apenas no menor $\mathrm{Ca}$ (2,5\%), $\left(\hat{Y}=15,8595+32,3342 X-35,0827 X^{2} ; R^{2}=0,88\right)$, comprovando que o nível de $0,46 \%$ de Pd na dieta proporciona maior porcentagem de Ca no tecido ósseo.

Garcia et al. (2000) testaram quatro níveis de $\operatorname{Pd}(0,27$ a $0,42 \%)$ combinados a quatro níveis de Ca (2,5 a 4,0\%) em dietas para codornas e observaram que a porcentagem de Ca nos ossos não foi influenciada $(\mathrm{P}>0,05)$ pelos níveis de Ca e P na ração, o mesmo observado por Abdallah et al. (1993) e Keshavarz \& Nakajima (1993).

Houve efeito da interação $(\mathrm{P}<0,01)$ níveis de $\mathrm{Ca} \times \mathrm{Pd}$ sobre a porcentagem de $\mathrm{P}$ nos ossos. Com o desdobramento da interação, as concentrações de P nos ossos foram influenciadas $(\mathrm{P}<0,01)$ pelos níveis de $\mathrm{Pd}$, tanto no menor nível $(2,5 \%)$ como no maior nível de Ca (3,2\%) testado. As dietas formuladas com 2,5\% de Ca proporcionaram aumento $(\mathrm{P}<0,01)$ na deposição de $\mathrm{P}$ no tecido ósseo das aves à medida que se aumentou o nível de Pd da dieta até o nível de $0,51 \%$ de Pd, conforme a equação ( $\hat{Y}=9,3616+4,289 X$ (reta); $\mathrm{R}^{2}=1,00 ; \hat{\mathrm{Y}}=11,5594$ (platô)), obtida pela aplicação do LRP. Quando se utilizou dieta com 3,2\% de Ca, o efeito dos níveis de Pd sobre o teor de P nos ossos foi quadrático $(\mathrm{P}<0,01)$, conforme a equação ( $\hat{\mathrm{Y}}=12,3365+13,2240 \mathrm{X}-$ $20,9595 X^{2}, R^{2}=0,90$ ), evidenciando que o nível de $0,32 \%$ de Pd minimiza o teor de P nos ossos.

Resultado semelhante foi observado por Garcia et al (2000) em codornas em postura. Esses autores observaram que os níveis de Pd na ração influenciaram de forma quadrática $(\mathrm{P}<0,05)$ a porcentagem de fósforo nos ossos e que a porcentagem de $\mathrm{P}$ nos ossos foi maior no nível de 0,35\% de Pd na ração.

Frost \& Johnston (1987), estudando galinhas poedeiras da $20^{\mathrm{a}}$ a $43^{\mathrm{a}}$ semana de idade, não encontraram efeito do nível de P na dieta sobre a concentração de Ca e P nos ossos das aves quando utilizaram dietas com 0,12 a 0,34\% de Pd. Barreto \& Hossain (1997), avaliando quatro níveis de Pd na dieta de duas linhagens de poedeiras comerciais, constataram que os níveis não influenciaram os teores de Ca e P no fêmur das aves. Entretanto, Scheideler \& Sell (1986), trabalhando com poedeiras, observaram diferença significativa para o percentual de $\mathrm{P}$ com o uso de dieta com níveis de 0,2 a $0,4 \%$ de $P d$.

\section{Conclusões}

Dietas com 2,5\% de Ca e 0,31\% de Pd são suficientes para proporcionar bom desempenho produtivo e manutenção satisfatória da qualidade dos ovos e do perfil nutricional do tecido ósseo de codornas japonesas na fase inicial de produção.

\section{Literatura Citada}

ABDALlAH, A.G.; HARMS, R.H.; HUSSEINY, O. Performance of laying eggs whit heavy or light shell weight when fed diets whit different calcium and phosphorus levels. Poultry Science, v.72, n.10, p.1881-1891, 1993.

BARRETO, S.L.T.; HOSSAIN, S.M. et al. Efeitos da concentração de fósforo disponível durante o pico de postura sobre o desempenho e a qualidade do ovo em duas linhagens de poedeiras comerciais leves. Arquivo Brasileiro de Medicina Veterinária e Zootecnia, v.49, n.3, p.343-352, 1997.

BARRETO, S.L.T.; PEREIRA, C.A.; UMIGI, R.T. et al. Determinação da exigência nutricional de cálcio de codornas japonesas na fase inicial do ciclo de produção. Revista Brasileira de Zootecnia, v.36, n.1, p.68-78, 2007.

CAVALHEIRO, A.C.L.; TRINDADE, D.S.; OLIVEIRA, S.C. et al. Níveis de fósforo em rações para poedeiras. Anuário Técnico do Instituto de Pesquisas Zootécnicas "Francisco Osório", v.10, p.7-16, 1983.

FROST, T.J.; JOHNSTON, N.P. Phosphorus nutrition in growing and laying chickens. Poultry Science, v.66, n.101, 1987 (suppl. 1).

FUGIKURA, W.S. Situação e perpectivas da coturnicultura no Brasil. SIMPÓSIO INTERNCIONAL DE COTURNICULTURA, 1. , 2002, Lavras. Anais... Lavras: Universidade Federal de Lavras, 2002. p.1.

GARCIA, J.; MURAKAMI, A.E.; MARTINS, E.N. et al. Exigências nutricionais de cálcio e fósforo para codornas japonesas (Coturnix coturnix japonica) em postura. Acta Scientiarum, v.22, n.3, p.733-739, 2000.

HAMILTON, R.M.G.; SIBBALD, I.R. The effects of dietary phosphorus on productive performance and egg quality of ten strains of white leghorns. Poultry Science, v.56, n.4, p.12211228, 1997.

INSTITUTO BRASILEIRO DE GEOGRAFIA ESTATÍSTICA IBGE. [2003]. Sistema IBGE de recuperação automática. Disponível em <http://www. Ibge.br/sidra> Acesso em: 30/8/2003.

JUNQUEIRA, O.M. Avanços recentes nas exigências de fósforo para poedeiras. In: CONFERÊNCIA APINCO DE CIÊNCIA E TECNOLOGIA AVÍCOLAS, 1993, Santos. Anais... Campinas: Fundação APINCO de Ciência e Tecnologia Avícolas, 1993. p.161-175. 
KESHAVARZ, K.; NAKAJIMA, S. Re-evaluation of phosphorus requirements of laying hens for optium performance and eggshell quality. Poultry Science, v.72, p.114-153, 1993.

LUZ, L.C.P. Variação granulometrica do calcário e diferentes níveis de cálcio em rações de codornas japonesas (Coturnix coturnix japonica). Lavras: Universidade Federal de Lavras, 2002. 58p. Dissertação (Mestrado em Zootecnia) Universidade Federal de Lavras, 2002.

MAGGIONI, R.; RUTZ, F.; PIECZARKA, V. et al. Interação entre cálcio e fósforo da dieta sobre o desempenho de poedeiras semipesadas. In: REUNIÃO ANUAL DA SOCIEDADE BRASILEIRA DE ZOOTECNIA, 35., 1998, São Paulo. Anais... Botucatu: Sociedade Brasileira de Zootecnia, 1998.

MASUKAWA, Y.; MORAES, V.M.B.; ARIKI, J. et al. Efeito dos níveis de cálcio sobre o desempenho produtivo e qualidade dos ovos de codornas japonesas (Coturnix coturnix japonica) In: CONFERÊNCIA APINCO DE CIÊNCIA E TECNOLOGIA AVÍCOLAS, 1996. Curitiba. Anais... Curitiba: Fundação APINCO de Ciência e Tecnologia Avícolas, 1996. p.35.

MASUKAWA, Y.; FERNANDES, E.B.; MORAES, V.M.B. et al. Níveis de cálcio da dieta sobre o desempenho e a qualidade da casca de ovos de codornas japonesas. Ars Veterinária, v.17, n.2, p.144-148, 2001.

MONGIN, P.; SAUVEUR, G. Plasma inorganic phosphorus concentration during eggshell formation. British Poultry Science, v.20, n.4, p.401-412, 1979.

MURATA, L.S. Granulometria do calcário e níveis de cálcio na qualidade da casca dos ovos de poedeiras comerciais. Jaboticabal: Universidade Estadual Paulista, 1995. 56p. Dissertação (Mestrado) - Universidade Estadual Paulista.

NATIONAL RESERCH COUNCIL - NRC. Nutrient requirements of poultry. 9.ed. Washington, D.C.: National Academy of Sciences, 1994. 155p.

OUSTERHOUT, L.E. Effects of calcium and phosphorus levels on egg weight and egg shell quality in laying hens. Journal of Poultry Science, v.59, n.7, p.1480-1484, 1980.

PEDROSO, A.; MORAES, V.M.B.; ARIKI, J. et al. Efeito de níveis dietéticos de cálcio e fósforo disponível sobre o desempenho e qualidade dos ovos de codornas japonesas. Ars Veterinária, v.15, n.2, p.135-139, 1999.
PINTO, R.; FERREIRA, A.S.; DONZELE, J.L. et al. Exigência de metionina mais cistina para codornas japonesas em postura. Revista Brasileira de Zootecnia, v.32, n.5, p.1166-1173, 2003a.

PINTO, R.; FERREIRA, A.S.; DONZELE, J.L. et al. Exigência de lisina para codornas japonesas em postura. Revista Brasileira de Zootecnia, v.32, n.5, p.1182-1189, 2003b.

RODRIGUEZ, M.; OWINGS, W.J.; SELL, J.L. Influence of phase feeding available phosphorus on egg production characteristics, carcass phosphorus content, and serum inorganic phosphorus levels of three commercial layer strains. Poultry Science, v.63, n.8, p.1553-1562, 1984.

ROLAND, SR.D.A.; HARMS, R.H. The influence of feeding diets containing different calcium-phosphorus ratios on the laying hen. Poultry Science, v.55, n.2, p.637-641, 1976.

SCHEIDELER, S.E.; SELL, J.L. Effects of calcium and phasefeeding phosphorus on production traits and phosphorus retention in two strains of laying hens. Poultry Science, v.65, n.11, p.2110-2119, 1986.

SHRIVASTAV, A.K.; PANDA, B. Level an sources of calcium for egg production and shell quality in quails. Indian Journal Poultry Science, v.21, n.1, p.78-81, 1986.

SILVA, D.J. Análises de alimentos (métodos químicos e biológicos). Viçosa, MG: Universidade Federal de Viçosa, 1998. $166 \mathrm{p}$.

UNIVERSIDADE FEDERAL DE VIÇOSA - UFV. Central de Processamento de Dados (UFV/CPD). Manual de utilização do programa SAEG (Sistema para Análises Estatísticas e Genéticas). Viçosa, MG: UFV, 2004. 59p.
Recebido: 18/9/2006 Aprovado: 15/6/2007 